\title{
Course Evaluation Generator (CEG): An Automated Academic Advising System with Optical Character Recognition
}

\author{
Cristopher C. Abalorio* \\ Program Head for Computer Science, \\ ACLC College of Butuan, \\ Butuan City, Philippines
}

\author{
Monalee dela Cerna \\ Program Chair in College of \\ Engineering and Information Technology, \\ Surigao State College of Technology, \\ Surigao City, Philippines
}

\begin{abstract}
This research aims to explain the requirements of constructing software intended for the teaching department of ACLC College of Butuan (ACB) to optimize the course selection process, lessen the academic advisor's time and effort, and give an accurate result in academic advising. Course Evaluation Generator (CEG) solved the issues encountered in course advising: incorrectness in crediting courses, manual automation in generating courses to offer, and manual evaluation of the remaining courses of a program. The CEG used Tesseract Optical Character Recognition (OCR) to read text from the academic transcript (TOR) by transforming the text into a digital image. To test the prototype constantly, this paper used the RAD approach in the development. The system was tested, deployed, and evaluated by the user respondents. Using the ISO 25010, the weighted mean for accuracy is 3.14 that user-respondents have strongly agreed to the correctness of generating courses to offer for a student. Even though the system itself has met the required functions and features using the Tesseract, the respondents and researchers suggest that more advanced machine learning should be integrated to enhance this study for future research.
\end{abstract}

Keywords: Academic Advising System, OCR, Evaluation, RAD Approach

Received: 13 June 2018; Accepted: 2 August 2018; Published: 20 October 2018

\section{INTRODUCTION}

Many students do not finish college in several nations. A survey conducted by PHILAMLIFE in 2017 showed that only $23 \%$ of Filipinos finish college. Financial issues always top the reasons why few students are able to complete the academic requirements to finish a degree. Somehow, college transfers found to be a relevant factor prompting for a longer stay in programs. One study by [1] listed switching majors as one of the reasons leading to the college transfer circumstances. Changing of majors affects how course credits are counted and often need additional coursework to satisfy the degree requirements. The significant ineffectiveness in the traditional academic advising procedure in the tertiary-level nowadays often resulted in high levels of student disappointment as stated by $[2,3]$. Although the Commission on Higher educa- tion (CHED) provides policies for course credit to college transfers still Community Colleges, State Universities and State Colleges, and other Professional Institutes such as Private Schools vary in course credit policy. Another issue is about the course descriptions and credit unit differences in the course curriculum offered by different schools that resulted in less course credit. Therefore, it escalates the probability of the student staying more years in school. Organizations have long recognized the importance of automated systems in almost all the transactions within it. The study of [2] suggested in creating the custommade interactive advising modules to allow students to complete advising-related tasks under the guidance of a program written by advisers. Automated software/system has now moved to its rightful place as a key resource. People are beginning to understand that application pro-

${ }^{*}$ Correspondence concerning this article should be addressed to Cristopher C. Abalorio, Program Head for Computer Science in ACLC College of Butuan, Butuan City, Philippines. E-mail: sircabalorio@ gmail.com

(c) 2018 The Author(s). Published by KKG Publications. This is an Open Access article distributed under a Creative Commons AttributionNonCommercial-NoDerivatives 4.0 International License. 
gram, which automates the manual transactions, is not just a by-product in conducting business; rather, it fuels organizational transactions and can be the critical factor in determining the efficiency and the failure of the organization.

ACLC College of Butuan (ACB), a member of AMA Education System, in Butuan City, Philippines is one of the fast-growing professional institutes in the Caraga region. A survey in 2016 showed that it had ranked number two (2) in the most number of enrollees on all ACLC branches nationwide. Because of the increasing population of enrollees every term or semester, the Institute has made a large scale regarding manpower requirement [4? ]. Basic school transactions in the enrollment system such as subject loading have been fully automated, yet some related issues existed in the area that affects school's efficiency in accepting a vast number of students in the enrollment period. The manual process in academic advising had been an issue since then because it is one of the crucial parts of choosing appropriate course suitable to be taken by the enrolling student. As a result, problems encountered in the academic advising have been specified which are the following: 1) Correctness in crediting courses; 2) Automation on course credit; and 3) Evaluation of the remaining courses.

To the most, Course Evaluation Generator (CEG): An Automated Academic Advising System with Optical Character Recognition (OCR) is a software application used for the pre-enrollment process. Hence, the title itself explains that automated academic advising works by analyzing student records of course, grades and earned units to generate course subjects that are required upon enrolling in every term or semester. It also has Optical Character Recognition feature that reads text-image from a hardcopy of an academic transcript/transcript of records (TOR) and translates or converts it into a digital text as input for course analysis.

This research project explains the requirements of constructing a software intended for the Teaching Department of ACB to optimize the course selection process; to lessen the time and effort spent by the academic advisor, and to give an accurate result in academic advising.

\section{REVIEW OF RELATED LITERATURE}

In the advent of flexible curriculum systems in many Higher Educational Institutions (HEI) and an ever broader range of courses and programs being offered, there is a current requirement to ensure that students make the best usage of obtainable information to make more knowledgeable decisions regarding their educational plan. In recent years, academic advising has been an important research area. The study of [2] presents that there are three models of academic advising which are the developmental, prescriptive and intrusive wherein advisor is informed by the purpose of the person in charge for academic advising and the student. All of the models build an educational partnership between the student and the advisor. Every Tertiary-level Institution requires an effective mechanism in academic advising, to boost the student development, which is beneficial for enrollment, retention, and rates of graduation. Several HEI offers academic advising system intended to aid the students and their advisors endorsed learning resources; and evaluate degree requirements to the student's status towards the anticipated degree. However, current advising support software tools can enhance the student-advisor relationship, but never and should not substitute in-person advising.

The idea of [5] assists the Researcher on assessment of the current academic advising. It helps the proponent to visualize the flow of the current advising system and supports for helping analyze how to solve the problem.

Several applications had been developed in webbased, or stand-alone applications for academic advising systems such as [2] which is to provide a reliable interface for treating the general advisory cases in the particular degree program offered by the Faculty of Science and Technology in the University of West Indies. The notion is to create a web semantic expert system in an academic advisory. This study [2] gives an impact on the concept of creating a system like an expert system capable of assisting the advisor.

The study of [6] highlighted the involvement of the student to select the applicable courses to enroll. The authors developed a Self-advising system that upholds the participation of the student in the academic advising, although the role of the human advisor is not substituted the involvement of the in-person advising, it helps the person who desires to enroll to interact with the system, which is a web-based system powered by JSON. Another web-based application is the study of [7] that uses NeuroFuzzy System as a method to design an online course advisory. The authors believed that the course advisor should comprehend the student's requirements, concern, and other relevant reasons. Therefore, connection with the course advisor is a contributing factor in an effective academic advisory. The study [8] designs a new model for e-Academic advising system for the web-based application. They proposed a model that composed of the complaint process, evaluate the procedure and suggestion process which aiming the system to support and facilitate the student.

The studies $[6,7,8,9]$ helps the Researcher on how 
significant the intervention of the student and the academic advisor in producing better course advice. The interactions of both parties showed importance in the procedure. Most of their system is developed in an onlinebased application, yet the application can also be designed for a desktop application.

Much advancement has been establishing efficient methods in academic advising like [10] that used an algorithm as a technique for constructing a decision tree towards academic advising. They developed a system that will endorse to the student the appropriate course to enroll in checking likenesses between the course taken by the student and the store course in each department and also [10] used the rule-based expert system to design an expert system for academic advisory. This method comprises the framework of a knowledge base and a rule interpreter in resolving problems in the inaccuracy of advising. The study [11] created a prototype for introducing a computerized approach for the procedure of academic advising. The authors used an Object-Oriented Approach and Rule-based prototype dedicated to assisting the new and incoming students to choose the most suitable major course and even the most suitable institution they can enroll.

The advancement of $[11,10,12]$ studies have great results in improving the efficiency of producing better course advice. The authors used different algorithms, methods, and approach in creating a prototype. Their studies help the Researcher to be opened-up in the possibility that academic advising can be developed in many technologies and advancements like the integration of [13] in the academic advising.

The advent of text-reading technology can contribute to active academic advisor such as the used of Optical Character Recognition. Integrating this relevant technology can improve the automation. Furthermore, many studies had been conducted for text-reading. Like [14] which presented a study which Optical Character Recognition (OCR) used to detect text. [13] presented a result of a survey paper on the reliability of OCR. This method allows the machine to automatically identify the characters through mechanical or electronic conversion of scanned images of handwritten, typewritten or printed text into digital or machine-encoded text. The review presented that OCR is useful for applications that are relevant in the area of character recognition. Implementations of OCR like [15] that used Optical Character Recognition technology to read and trace the E-code of a product that is of halal. A study that develops a mobile application to get the E-code of the halal products to identify the additives being used in the manufacturing. [16] also developed a project with different techniques that the OCR can be used such as Maximally Stable Extremal Regions (MSER) that is used for numerous applications like traffic sign detection and number plate detection. [17] implemented the License plate recognition application using EmguCV using the OCR.

The study $[13,15,16,17]$ are implementations of optical character recognition which gave the substantial support that this technology is helpful upon designing the concept of academic advising. OCR is entirely not new in the field of computing yet no single study integrates this technology in solving the problems in the traditional way of academic advising system.

\section{METHODS AND MATERIALS}

In the development of this paper Rapid Application Development (RAD) approach was used because there is a constant testing of the prototype needed. The framework of the study shows how the system works.

In Fig 1 the components of the system architecture, the concept of this system is to create an automated an automated Academic Advisory for students in every term or semester. The system will generate results by either of the two inputs: the user input from Academic Advisor which uses records from Student Evaluation Records (containing earned units and grades); and input from extracted text from the scanned image of a Transcript of Records. Both input types will undergo the process of system's course advisory through the policy and procedures for giving a suitable course.

The following are the components of the system: 


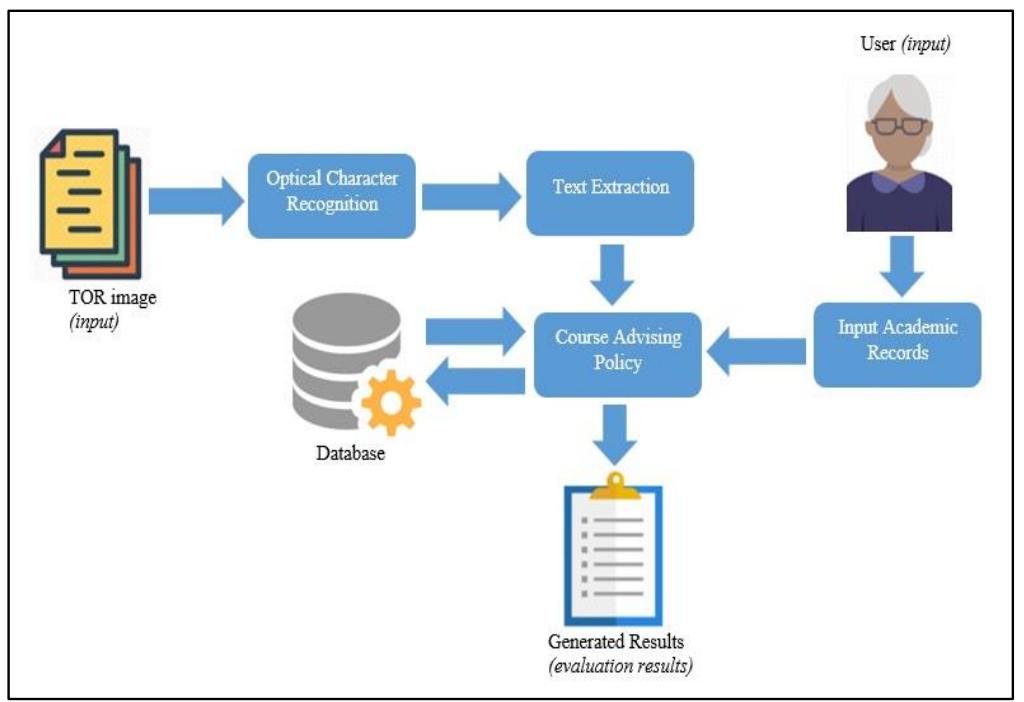

Fig. 1. The Framework of the study

\section{A. Image of the Transcript of Records}

Copy of the transcript of record is called the academic transcript which lists the earned course description, corresponding units with grades obtained by the student. It shows whether the student was able to pass or failed the course. The image is the substantial input which needs to be scanned to extract its text to initiate the process.

\section{B. Optical Character Recognition}

Optical character recognition (OCR) is a method used to convert printed text into editable text. OCR is very suitable and standard methods in various applications. The correctness of OCR can be very reliant on the text preprocessing and segmentation algorithms. Occasionally it is challenging to retrieve text from the image because of different size, style, orientation, the complex background of the image, etc. This project applied Tesseract OCR in the system for text extraction. The OCR can extract text from scanned images of typewritten text. There are four essential techniques in constructing the OCR:

1) Preprocessing: Overall function for this is to scan and recognize the processed image and transform into bitmap file or binary matrix from its original text. The text analysis and procedures apply in each section of the text image into line and characters.

2) Self-learning: Current OCR systems have this utility to improve the knowledge when an unknown character is encountered; character recognition is based on the database formerly built in, which comprises the vital features related to the characters which are identified already. It is required that the database can self-expand further, and more new characters are encountered to increase the recognition capacity. It is implemented by adding new characters features and their human-given values into the database.

3) Recognition: This is the central portion of the process. It gets input character and compares these features from those stored in the database. If the features are matched or nearly matched, the input character is categorized into a class within the standard features on it . The classification frequently falls into numerous phases. The last phase is called final classification while others are called broad classification. After the final classification, and individual character is sorted as a result.

4) Post-processing: The ASCII text containing both the recognized and unidentified characters usually requires editing and revision. The purpose of this step is to change and correct mistakes, as they commonly appear after the recognition phase, and give their meaning (ASCII characters) to the unidentified characters.

\section{Text Extraction}

Text extraction is the process used after the OCR. It merely transfers the text into an array. The used of Regular Expressions is integrated with this step. A regular expression is a fundamental concept in computer science used for matching strings of character such as texts coming from TOR.

\section{Course Advising Policy}

It refers to the policy implemented in ACB. This policy is in adherence to the CHED standard policies on how courses are credited in an institution. It is the rule being set in the framework to allow or permit the course to credit. 


\section{E. Database}

The database in the framework is served as the repository. The essential part for the process is it stores the dynamic set of curriculum for a particular program being offered in the HEI. It also stores the courses, grades, and units which needed to be checked upon crediting the course.

\section{F. Generated Results}

The generated results are the output of the framework. It is the outcome of the academic advising.

\section{G. Input academic records}

This is the portion the grades are stored in the system.

\section{H. User}

It is the end-user of the system. It refers to the intervention of the academic advisor to the system.

Table 1 shows that the total number of respondents is fifteen (15) people. These people are the front-liners in the enrollment process: the School registrars and its staff; the Dean and the Program heads who manage the courses in each respective Programs; and the members of the Faculty in Teaching Department.

TABLE 1

DISTRIBUTION OF RESPONDENTS

\begin{tabular}{lll}
\hline Respondent & N & Percentage \\
\hline School Registrar \& Staff & 3 & $20 \%$ \\
Dean and Program Heads & 5 & $33.33 \%$ \\
Faculty \& Staff & 7 & $46.67 \%$ \\
Total & 15 & $100 \%$ \\
\hline
\end{tabular}

\section{RESULTS AND DISCUSSION}

A. Specimen of the Transcript of Records

Fig 2 displays the specimen of scanned images (from left to right) of TOR from ACLC College of Butuan
(Butuan City), San Pedro College (Davao City), Philippine Electronics and Communication Institute of Technology (Butuan City), and University of the City of Manila (Manila).

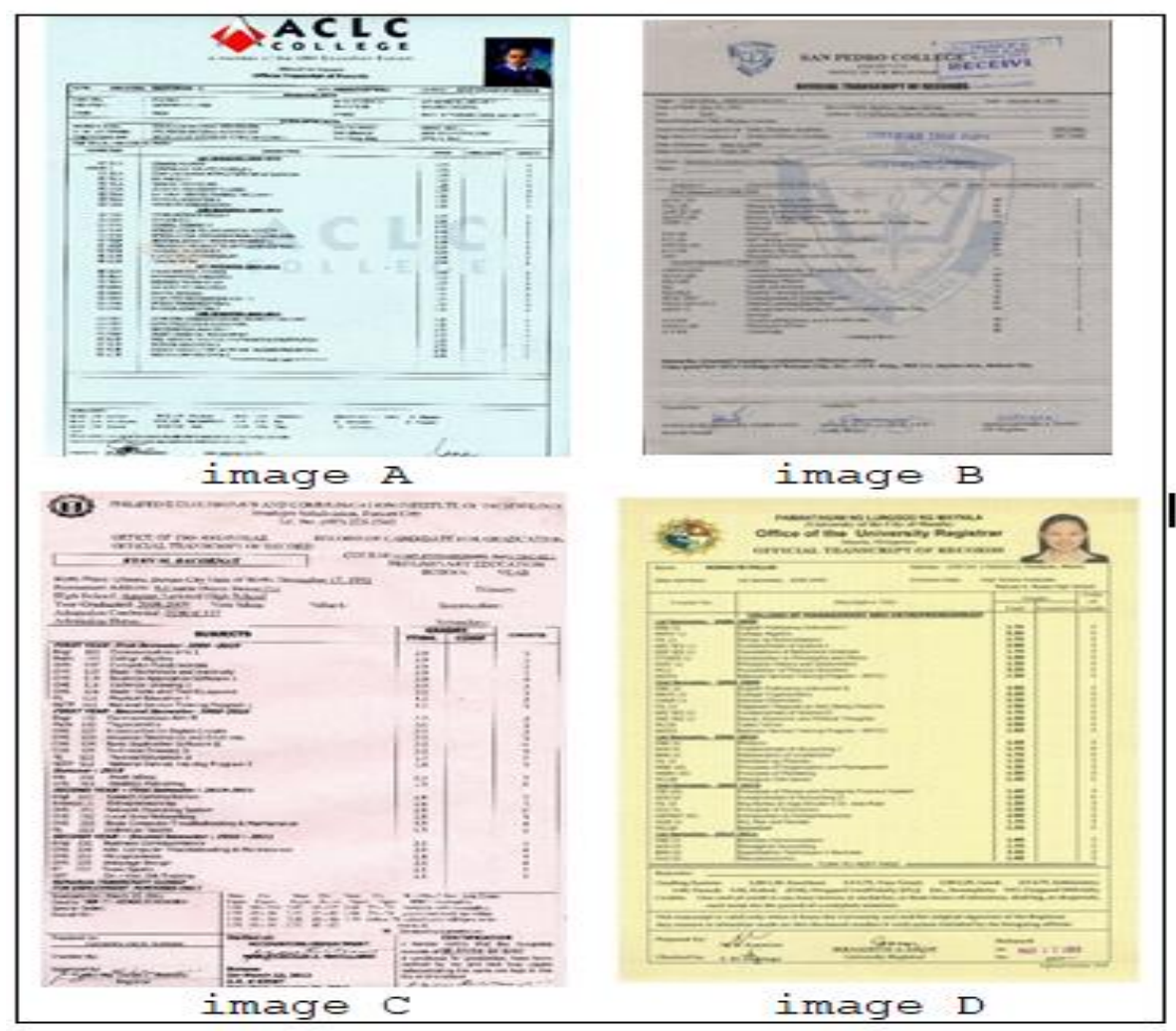

Fig. 2. Sample TOR 
B. Result of the Image Specimen using the CEG Application

In Fig 3 After importing and reading this image from the file, there were twenty-seven (27) courses read and existed both in the specimen's texts and in the selected program (BSCS) of the curriculum.

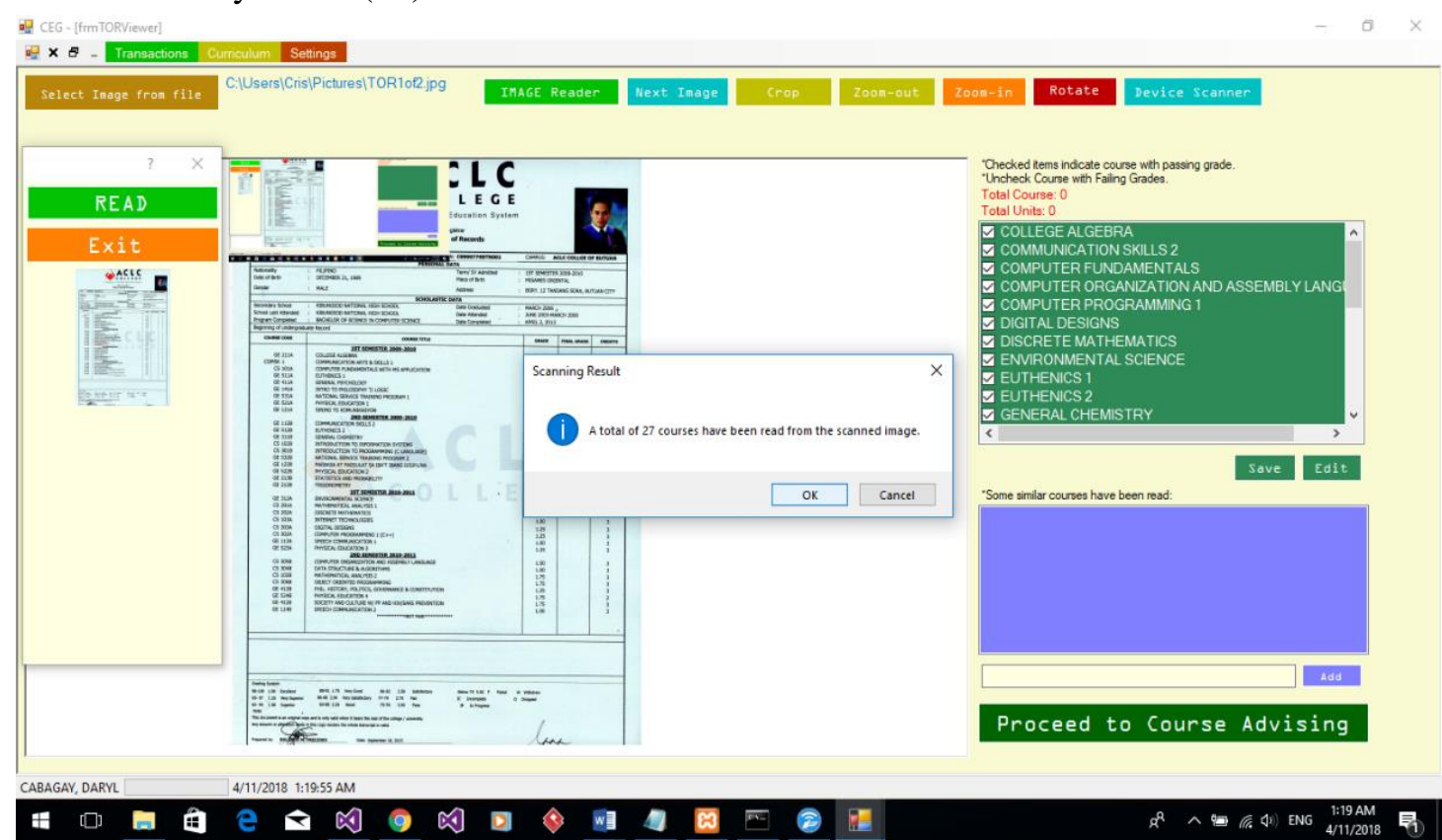

Fig. 3. Sample TOR
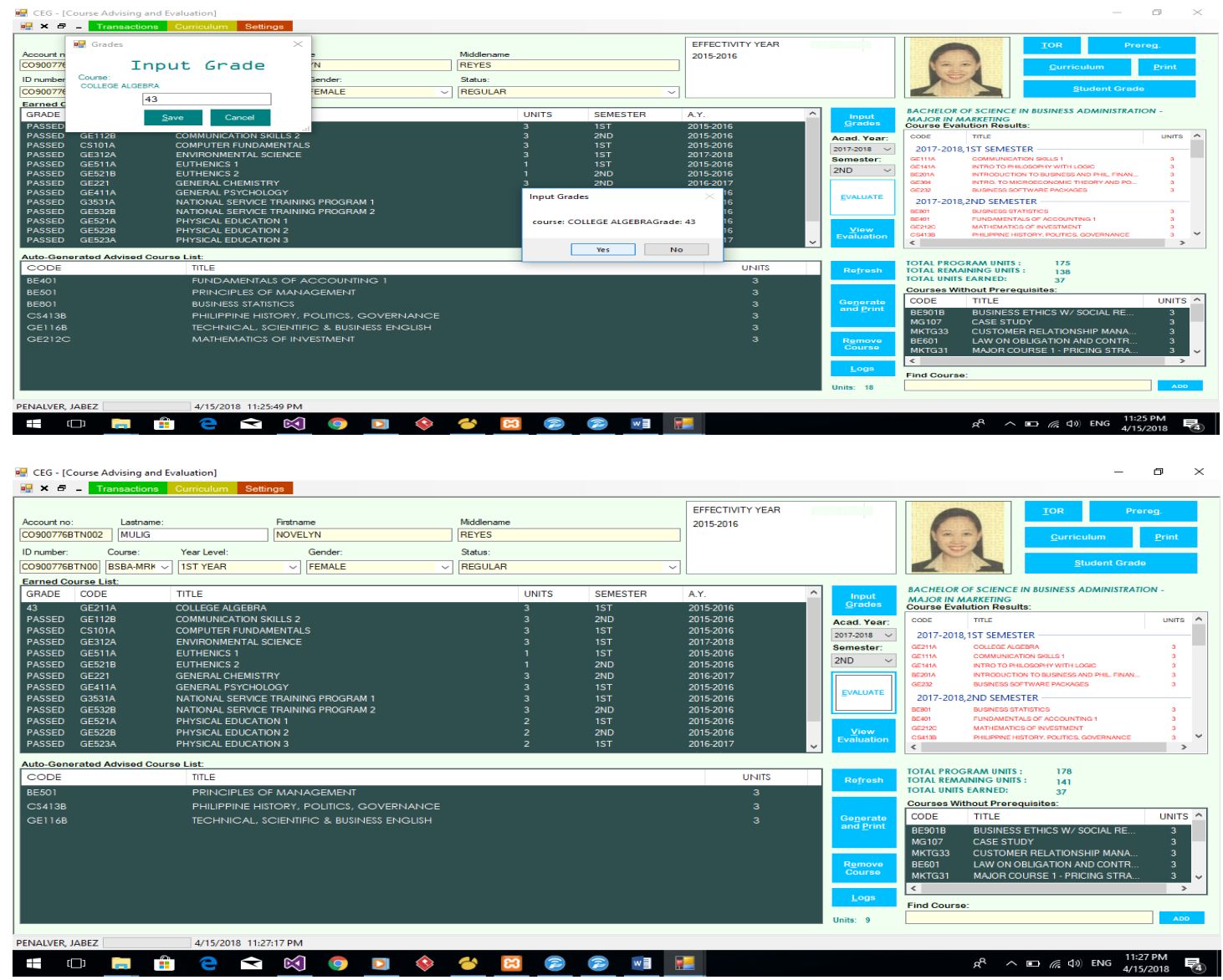

Fig. 4. Course with a required course (pre-requisites) 
Fig 4 shows the course College Algebra has updated its grade from passed to failed grade. In the bottom figure in its bottom-left list container courses such as Fundamentals of Accounting 1, Business Statistics, and Mathematics of Investment was removed automatically from the generated course advice list container because College Algebra is a required course for this program.

\section{ANALYSIS OF THE RESULTS OF THE SCANNING}

Table 2 shows the result of the testing of the image specimen. The scanning fluctuates in the different test result. Some of the reasons is that transcript of records on different Higher Education have different structure especially in tabulating of text and letters; and also, in putting the logo and abbreviation of the school name in the background as an in-place watermark.

TABLE 2

TEST RESULT TABLE

\begin{tabular}{llll}
\hline Image Specimen & Read Course & Unread Course & Findings of Unread Course \\
\hline Image A & 27 & 0 & N/A \\
Image B & 4 & 0 & N/A \\
Image C & 7 & 0 & N/A \\
Image D & 0 & 1 & Poor Image Quality \\
\hline
\end{tabular}

\section{CONCLUSION AND RECOMMENDATIONS}

The study showed that by combining the image processing technology of Optical Character Recognition engines with the institutional policy of course crediting, an automated course generator was developed. The OCR read text from scanned images and the internal policy performs the evaluation through course comparison using the curriculum data of course description, grades, pre-requisites, and credit units. This integration constituted the vital components in the implementation of the CEG software. The study was able to produce a dynamic course advisory for programs offered by the academic institution. Even if schools offered different course descriptive titles in their curriculum, the used of regular expressions helped the implemented software to query the substrings of the course name being searched resulting to trace similar course title to credit.

The study concluded that crediting courses from the scanned image of TOR is feasible using the right policy and text image quality acquisition. A weighted mean of 3.41 interpreted as "strongly agree" by the userrespondents of the system with regards to the accuracy in generating course advice. This means that CEG software has met the requirement and its features are all operational, functional, and provides an accurate result. Even though the system itself has met the required functions and features using the Tesseract the Respondents and Researchers suggest that more advanced machine learning should be integrated to enhance this study for future research.

\section{Declaration of Conflicting Interests}

There are no conflicts of interest.

\section{Acknowledgments}

The Researcher would like to give back all the Honor and Glory to Almighty God for the wisdom. Moreover, the Researcher would like to acknowledge the following:

1. To Dr. Monalee A. dela Cerna for the guidance and sincere suggestions to make this study more interesting and challenging;

2. To my Family for providing an unfailing support and continuous encouragements in the challenges encountered.

\section{REFERENCES}

[1] D. K. Moldoff, "Top 10 reasons why students transfer," 2018. [Online]. Available: https://bit.ly/2EhcWvL

[2] L. K. Henderson and W. Goodridge, "Adviseme: An intelligent web-based application for academic advising," International Journal of Advanced Computer Science and Applications, vol. 6, no. 8, pp. 233-243, 2015. doi: https://doi.org/10.14569/ijacsa. 2015.060831

[3] R. Styron Jr, "Student satisfaction and persistence: Factors vital to student retention," Research in Higher Education Journal, vol. 6, pp. 1-18, 2010.

[4] M. A. Maderazo, "The change management in an academic institution: An organizational perspective," Journal of Advances in Humanities and Social Sciences, vol. 2, no. 6, pp. 310-320, 2016. doi: 
https://doi.org/10.20474/jahss-2.6.3

[5] O. Iatrellis, A. Kameas, and P. Fitsilis, "Academic advising systems: A systematic literature review of empirical evidence," Education Sciences, vol. 7, no. 4, p. 90, 2017.

[6] G. Vincenti and V. Bennett, "A JSON-based selfadvising system," Journal of Computing Sciences in Colleges, vol. 32, no. 3, pp. 39-45, 2017.

[7] V. Vaidhehi, "A framework to design a web based neuro fuzzy system for course advisor," International Journal of Innovative Research in Advanced Engineering, vol. 1, no. 1, pp. 186-190, 2014.

[8] E. Afify and M. Nasr, "A proposed model for a webbased academic advising system," International Journal of Advanced Networking and Applications, vol. 9, no. 2, pp. 3345-3361, 2017.

[9] C. L. S. Tablatin, F. F. Patacsil, and P. V. Cenas, "Design and development of an information technology fundamentals multimedia courseware for dynamic learning environment," Journal of Advances in Technology and Engineering Studies, vol. 2, no. 5, pp. 202-210, 2016. doi: https://doi.org/10.20474/ jater-2.6.5

[10] M. Al-Sarem, "Building a decision tree model for academic advising affairs based on the algorithm C 4-5,” 2015. [Online]. Available: https://bit.ly/2SqjqNK

[11] Y. Bouaiachi, M. Khaldi, and A. Azmani, "A prototype expert system for academic orientation and student major selection," International Journal of Scientific \& Engineering Research, vol. 5, no. 11, pp. 25-28, 2014.
[12] J. Hell, "Advaisor: A rule based expert system for academic advising," Ph.D. dissertation, 2016.

[13] S. Pansare and D. Joshi, "A survey on optical character recognition techniques," International Journal of Science and Research (IJSR), vol. 3, no. 12, pp. 1247-1249, 2014.

[14] R. Baran, P. Partila, and R. Wilk, "Automated text detection and character recognition in natural scenes based on local image features and contour processing techniques," in International Conference on Intelligent Human Systems Integration, Dubai, United Arab Emirates, 2018. doi: 10.1007/ 978-3-319-73888-8_8 pp. 42-48.

[15] L. Meng Chun, S. Muhammad Nizam, H. Arshad, S. Ahmad Shukri, N. Che Hashim, and H. Putra, "A usability evaluation of an interactive application for halal products using optical character recognition and augmented reality technologies," in 2nd International Conference on Applied Science and Technology, ICAST, Langkawi, Kedah, Malaysia, 2017. doi: 10.1063/1.5005417

[16] J. Ghorpade-Aher, S. Gajbhar, A. Sarode, G. Gayake, and P. Daund, "Text retrieval from natural and scanned images," International Journal of Computer Applications, vol. 133, no. 8, pp. 10-12, 2016.

[17] N.-W. Kim and C.-W. Hur, "Study on performance evaluation of automatic license plate recognition program using emgu cv," Journal of the Korea Institute of Information and Communication Engineering, vol. 20, no. 6, pp. 1209-1214, 2016. 